\title{
Dabigatran and warfarin in nonvalvular atrial fibrillation or atrial flutter in outpatient clinic practice in Brazil
}

\author{
Dabigatrana e varfarina em pacientes com fibrilação atrial não valvar ou flutter em \\ ambulatório especializado no Brasil \\ Jean Michell Correia Monteiro', Daniel Lordelo San-Martin', Beatriz Carneiro Gondim Silva', Ian Felipe \\ Barbosa Souza', Jamary Oliveira Filho², Pedro Jesus ${ }^{1}$
}

\begin{abstract}
Objectives: To compare warfarin and dabigatran for thromboembolic event prevention in patients with nonvalvular atrial fibrillation or atrial flutter. Methods: This was a retrospective cohort of participants with nonvalvular atrial fibrillation or atrial flutter using either warfarin or dabigatran in a reference center in Brazil. Results: There were 112 patients (mean age 65.5 years), with 55.3\% using warfarin. The median duration of follow-up was 1.9 years for warfarin and 1.6 years for dabigatran ( $p=0.167$ ). Warfarin patients had a higher median of medical appointments per year (8.3 [6.8-10.4] vs 3.1 [2.3-4.2], $p<0.001)$ and the frequency of minor bleeding was more than four times higher (17.7\% vs $4.0 \%, p=0.035)$. Among patients with prior stroke, those using warfarin had 2.6 times more medical appointments for person-years of follow-up (8.5 vs 3.3). There was no major bleeding or embolic event during follow-up period. Conclusion: The dabigatran group had a lower frequency of minor bleeding and number of medical appointments than the warfarin group, without more embolic events or major bleeding.
\end{abstract}

Keywords: Dabigatran; warfarin; atrial fibrillation; atrial flutter; stroke.

RESUMO

Objetivos: Comparar varfarina e dabigatrana para prevenção de eventos tromboembólicos em pacientes com fibrilação atrial não valvar ou flutter (FA). Métodos: Coorte retrospectiva de pacientes com FA em uso de varfarina ou dabigatrana em serviço especializado no Brasil. Resultados: Foram avaliados 112 pacientes (média idade 65,5), com 55,3\% no grupo varfarina. A mediana do tempo de seguimento foi de 1,9 anos para o grupo varfarina e 1,6 para dabigatrana $(p=0,167)$. No grupo varfarina houve maior mediana de consultas médicas (CM) por ano $(8,3[6,8-10,4]$ vs. $3,1[2,3-4,2], p<0,001)$, com frequência de sangramento menor quatro vezes maior $(17,7 \%$ vs. 4,0\%, $p=0,035)$. Nos pacientes com acidente vascular cerebral isquêmico prévio, o grupo varfarina teve 2,6 vezes mais CM por pessoas-ano de seguimento (8,5 vs. 3,3). Não houve sangramento maior ou eventos embólicos no período de seguimento. Conclusão: Pacientes em uso de dabigatrana tiveram menor número de sangramento menor e CM que aqueles em uso de varfarina, sem aumentar eventos embólicos ou sangramentos maiores.

Palavras-chave: Dabigatrana; varfarina; fibrilação atrial; flutter atrial; acidente vascular cerebral.

Atrial fibrillation and atrial flutter are common cardiac arrhythmias that increase the risk of thromboembolic events. Preventive therapy can be accomplished through oral anticoagulants with vitamin $\mathrm{K}$ inhibitors, such as warfarin, the main drug used for this purpose. Warfarin is difficult to manage because it has multiple food and medication interactions, a considerable frequency of interruptions, requires frequent laboratory monitoring and it is not uncommon to find the international normalized ratio (INR) outside the therapeutic range ${ }^{1}$.

In the last years, the introduction of new oral anticoagulants has marked a major change in therapy for patients with nonvalvular atrial fibrillation, providing an alternative to warfarin for prevention of arterial thromboembolism (ischemic stroke or systemic embolism). Large multicenter randomized controlled trials have demonstrated dabigatran etexilate ${ }^{2}$, rivaroxaban ${ }^{3}$ and apixaban ${ }^{4}$ to be noninferior, or even superior, to warfarin in stroke and systemic embolism prevention, with reduced bleeding rates.

Despite the RE-LY trial results ${ }^{2}$, to date there are a lack of data about dabigatran etexilate use in the Brazilian population for prevention of thromboembolic events, which makes the conduction of national studies in this area essential. This study aimed

${ }^{1}$ Universidade Federal da Bahia; Salvador BA, Brasil;

${ }^{2}$ Universidade Federal da Bahia, Departamento de Biomorfologia, Salvador BA, Brasil.

Jean Michell Correia Monteiro (iD https://orcid.org/0000-0002-2921-4577

Correspondence: Jean Michell Correia Monteiro; Universidade Federal da Bahia; Rua Waldemar Falcão, 1654; 40296-700 Salvador BA, Brasil; E-mail: jk_ michell@hotmail.com

Conflict of interest: There is no conflict of interest to declare.

Received 13 June 2018; Received in final form 16 October 2018; Accepted 07 November 2018. 
to compare these drugs for thromboembolic event prevention in patients with atrial flutter or nonvalvular atrial fibrillation.

\section{METHODS}

This was a retrospective cohort study of participants using dabigatran etexilate or warfarin followed in the outpatient clinics of Cerebrovascular Diseases and Cardiology at the Complexo Hospitalar Universitário Professor Edgard Santos in Salvador, Brazil, from January 2011 to December 2014. Patients were referred to these specialized services through the Brazil public health system network. Inclusion criteria were patients with nonvalvular atrial fibrillation or atrial flutter, using oral anticoagulation with warfarin or dabigatran etexilate and age $>18$ years. Exclusion criteria were the absence of follow-up period data, clinical and anticoagulation characteristics in the medical records. Patients with fewer than three medical appointments were excluded. The choice for warfarin or dabigatran was based on agreement among attending physicians from our service and patients, taking into consideration benefits, harm effects and costs of each medication. Only warfarin was available free of charge in our service. This study aimed to compare these two drugs, and other novel oral anticoagulants were not evaluated.

Primary outcomes were defined as an embolic event or major bleeding during the follow-up period, and secondary outcomes as the number of medical appointments per year or person-years of follow-up, an INR in the therapeutic range, drug change, poor adherence and minor bleeding. Sociodemographic, clinical and laboratory data were collected from medical records. Atrial fibrillation risk scores were calculated at baseline characteristics as $\mathrm{CHADS}_{2}$ (congestive heart failure, hypertension, age [ $\geq 75$ years], diabetes, stroke/ transient ischemic attack) ${ }^{5}$, $\mathrm{CHA}_{2} \mathrm{DS}_{2}-\mathrm{VAS}_{\mathrm{C}}$ (congestive heart failure, hypertension, age [ $\geq 75$ years], diabetes, stroke/transient ischemic attack, vascular disease, age [65-74 years], sex [ female]) ${ }^{6}$ and HAS-BLED (hypertension, abnormal renal/liver function, stroke, bleeding history of predisposition, labile INR, age $\geq 65$ years, drugs/alcohol concomitantly) ${ }^{7}$.
An INR within therapeutic range was defined as between 2.0 and 3.0. We defined inadequate adherence as the number of medical appointments in which the medical prescription was not used properly. Interruptions were drug discontinuation for any reason. Major bleeding was defined as fatal or symptomatic intracranial bleeding, transfusion or surgical intervention requirements. Gingival and genital bleeding, increased menstrual flow, or spontaneous hematoma that did not require transfusion or surgical intervention were considered minor bleeding ${ }^{2}$.

\section{Statistical analysis}

Groups were analyzed according to dabigatran etexilate or warfarin use. A longitudinal analysis was performed to evaluate the number of medical appointments per personyear of follow-up for total medical reviews, INR in range, interruption, adherence and bleeding. A transversal analysis was performed to compare clinical baseline characteristics and the median of medical appointments per year for total medical reviews, INR out range, interruption, adherence and bleeding. Student's t, Mann Whitney U, Fisher or chi-square tests were used when appropriate. Results were described as mean \pm squared deviation, median [interquartile range] or proportion (\%). The $\mathrm{p}$ value is shown for an exact and twotailed test. Analyses were done using SPSS 21.0.

This study was approved by the Research Ethics Committee of the School of Medicine of the Federal University of Bahia (Statement 856 694).

\section{RESULTS}

Data was obtained from 112 patients, with 62 (55.3\%) of them using warfarin. The mean age was 65.5 years $( \pm 12.3)$ and the female gender was almost half of the sample (49.1\%). Black ethnicity was reported in $24.6 \%$. Nonvalvular atrial fibrillation was classified as persistent in $86.7 \%$. The baseline characteristics between patients using warfarin or dabigatran etexilate are shown in the Table. Patients using warfarin had a median of $\mathrm{CHADS}_{2}$ of 3 [2-4], $\mathrm{CHA}_{2} \mathrm{DS}_{2}$ VASc of 4

Table. Baseline characteristics between warfarin and dabigatran etexilate patients.

\begin{tabular}{lccc}
\hline Characteristics & Warfarin $(n=62)$ & Dabigatran etexilate $(n=50)$ & $p$-value \\
\hline Age, mean \pm standard deviation & $64.2 \pm 11.4$ & $67.2 \pm 13.4$ & 0.199 \\
Female gender (\%) & 56.4 & 40.0 & 0.091 \\
Non-white ethnicity (\%) & 40.3 & 59.7 & 0.752 \\
Prior stroke (\%) & 35.5 & 42.0 & 0.559 \\
Chagas disease (\%) & 33.9 & 18.0 & 0.085 \\
Diabetes mellitus (\%) & 30.6 & 24.0 & 0.526 \\
Hypertension (\%) & 91.9 & 80.0 & 0.093 \\
Chronic renal disease (\%) & 11.3 & 6.0 & 0.508 \\
Coronary artery disease (\%) & 25.8 & 16.0 & 0.368 \\
Heart failure (\%) & 64.5 & 44.0 & 0.036 \\
Statins use (\%) & 41.9 & 40.0 & 0.702 \\
\hline
\end{tabular}


[3-5] and HAS-BLED of 3 [2-3]. Those using dabigatran, had a median of $\mathrm{CHADS}_{2}$ of 3 [1-4], $\mathrm{CHA}_{2} \mathrm{DS}_{2}$ VASc of 4 [2-6] and HAS-BLED of 2 [1-3].

The median time of follow-up was 1.9 years for the warfarin group [0.7-3.8] and 1.6 years for the dabigatran etexilate group [1.1-1.9] ( $\mathrm{p}=0.167)$. The median number of medical appointments per year was higher in warfarin patients (8.3 [6.8-10.4] vs 3.1 [2.3-4.2], $\mathrm{p}<0.001)$. Among patients using warfarin, $98.4 \%$ had more than four medical appointments per year and in those using dabigatran, this frequency was 30\% ( $\mathrm{p}<0.001)$. There was no major bleeding during the study period, but the frequency of minor bleeding was more than four times higher in warfarin patients than in dabigatran etexilate patients ( $17.7 \%$ vs $4.0 \%, p=0.035$ ). The median INR outside the therapeutic range per year was 4.3 [2.6-6.6]. The median frequency of medical appointments with an INR within the therapeutic range was $50.0 \%$ during all follow-up periods.

In a longitudinal analysis, the warfarin group had 7.9 medical appointments per person-year of follow-up and the dabigatran etexilate group had 3.1. Among patients with prior ischemic stroke $35.6 \%$ in the warfarin group and $42 \%$ in the dabigatran group), those using warfarin had 2.6 times more medical appointments per person-year of follow-up (8.5 vs 3.3). Minor bleeding occurred in 11 patients in the warfarin group and two patients in dabigatran group. In the warfarin group, $35.5 \%$ of patients interrupted their medication at some point during their follow-up, and the dose was changed in $95.2 \%$. Of the patients in the warfarin group, $61.3 \%$ failed to follow medical instructions regarding medication use. The number of medical appointments with an INR in the therapeutic range was 4.2 per person-year of follow-up.

In the dabigatran group, $46 \%$ started with $150 \mathrm{mg}$ twice a day. The dose was decreased in 12 (24\%) patients due to reduced creatinine clearance in two patients, minor bleeding in two, dyspepsia in one and for other medical reasons in the remainder. The drug was stopped in 11 patients $(22 \%)$ because four patients could not afford to buy it, one had dyspepsia, one had reduced creatinine clearance and for other medical reasons in the remainder. During the follow-up period, 8 (16\%) patients complained of dyspepsia.

There was no major bleeding during the follow-up period. However, two patients in the dabigatran etexilate group had an embolic ischemic stroke after stopping medication. One patient interrupted their dabigatran use for their own reason and had a new embolic event eight weeks later. In the other patient, dabigatran was suspended, and changed to warfarin immediately, due to reduced creatinine clearance levels. This patient had an embolic ischemic stroke eight days after stopping medication and required hospitalization, during which they had other events, and died from complications. These patients were censured before the events, due to the absence of medical records after the events.

In the dabigatran group, the prior use of warfarin was reported in 9 (38\%) patients. There was insufficient data about patients using one medication and changing to another during the follow-up period to enable analysis.

\section{DISCUSSION}

This is the first published study to compare warfarin and dabigatran etexilate in nonvalvular atrial fibrillation and atrial flutter for prevention of thromboembolic events in Brazil. We studied 112 patients, of whom 62 used warfarin and 50 used dabigatran etexilate. Warfarin patients presented with a greater frequency of medical appointments and minor bleeding. There was no major bleeding, but two embolic events occurred in the dabigatran etexilate group, both due to discontinuation of this drug, with one death from complications. There was no recurrence of an event in the warfarin group. The follow-up period was similar and the rates of drug discontinuation were more frequent in the warfarin group, but less common in the dabigatran group when compared with previous studies ${ }^{2,8,9,10}$.

Dabigatran etexilate requires fewer medical appointments because it is not necessary to monitor the INR, and previous studies have found that using $150 \mathrm{mg}$ twice daily reduced the risk of stroke ${ }^{2}$ or systemic embolic events, compared with warfarin, thus reducing the hospitalization cost. Due to these characteristics, lower total event costs, and lower long term follow-up costs per patient, Clemens et al. concluded that dabigatran etexilate was cost-effective when compared with warfarin in US patients with atrial fibrillation at any age ${ }^{11}$.

Side effects were not common in this study, probably due to the small sample size. Only dyspepsia was found in $16 \%$ of the dabigatran group, while the warfarin group did not report any side effects, except minor bleeding. In the RE-LY trial by Connolly et al., many adverse events were reported that were not found in our sample, but they did find a smaller frequency of dyspepsia ${ }^{2}$. Minor bleeding happened in $17.7 \%$ of our warfarin group and $4 \%$ in the dabigatran group. Major bleeding did not happen in our sample. Our results are consistent with a recent meta-analysis that showed that dabigatran etexilate use is not associated with bleeding issues in atrial fibrillation patients ${ }^{12}$. However, interruption due to cost was very significant in our sample, with $22 \%$ of patients changing treatment.

In a retrospective cohort of patients with atrial fibrillation using dabigatran $(n=1,302)$ or warfarin $(8,102)$, dabigatran use was associated with a higher risk of any bleeding (hazard ratio (HR): 1.30, IC 95\% 1.20-1.41) and major bleeding (HR: 1.85, IC 95\% 1.64-1.41), but with a lower risk for intracranial hemorrhage (HR: 0.32, IC 95\% 0.20-0.50). These risks were greater in African Americans and patients with chronic kidney disease ${ }^{13}$. In our sample, the risk for minor bleeding was higher in warfarin patients, with no reports of major bleeding. Despite the small sample and a reduced statistical power 
in this study, contradictory results may have been due to the characteristics of the Brazilian population.

Our results show similarities to previous studies regarding the follow-up period, minor bleeding and less frequent medical appointments. Some disagreements, such as the absence of major bleeding and only one death, were possibly due to the small sample size in our study. Another limitation was the impossibility of standardizing anticoagulation treatment among patients, which can create concerns about the potential source of confounders. Nevertheless, our results showed that dabigatran etexilate can be used in the Brazilian population in nonvalvular atrial fibrillation and atrial flutter, with a lower frequency of minor bleeding, compared with warfarin, and a rare occurrence of major bleeding, hospitalization and death. Another important result is the less frequent medical appointments, which leads to lower long-term follow-up costs per patient-especially important in the public health system.

This study was not adequately designed to show dabigatran's efficacy and safety and more studies in the Brazilian population are needed. Among the patients taking warfarin, there was a higher frequency of women, heart failure and
Chagas disease than those taking dabigatran. We believe this higher percentage of women was due to the small sample and the impossibility of adjusting the protocol before use. The frequency of heart failure can be explained by the higher incidence of Chagas disease in the warfarin group. The lack of studies within this population may explain the lower indication for dabigatran in this subgroup of patients, which generates selection bias. We did not carry out an adjusted analysis due to the fact that the data model presented important limitations for using a multivariate analysis with continuous outcomes, which would have led to dubious results.

In conclusion, patients using dabigatran etexilate had a lower frequency of minor bleeding and number of medical appointments than those in the warfarin group. There was no difference in major bleeding, hospitalization and deaths between the groups during follow-up.

\section{ACKNOWLEDGMENTS}

We thank the Neurology Academic League of Federal University of Bahia (LAN - FMB) for their support.

\section{References}

1. Hart RG, Pearce LA, Aguilar MI. Meta-analysis: antithrombotic therapy to prevent stroke in patients who have nonvalvular atrial fibrillation. Ann Intern Med. 2007 Jun;146(12):857-67. https://doi.org/10.7326/0003-4819-146-12-200706190-00007

2. Connolly SJ, Ezekowitz MD, Yusuf S, Eikelboom J, Oldgren J, Parekh A, et al. Dabigatran versus warfarin in patients with atrial fibrillation. N Engl J Med. 2009 Sep;361(12):1139-51. https://doi.org/10.1056/NEJMoa0905561

3. Patel MR, Mahaffey KW, Garg J, Pan G, Singer DE, Hacke $W$, et al. Rivaroxaban versus warfarin in nonvalvular atrial fibrillation. N Engl J Med. 2011 Sep;365(10):883-91. https://doi.org/10.1056/NEJMoa1009638

4. Granger CB, Alexander JH, McMurray JJ, Lopes RD, Hylek EM, Hanna M, et al. Apixaban versus warfarin in patients with atrial fibrillation. N Engl J Med. 2011 Sep;365(11):981-92. https://doi.org/10.1056/NEJMoa1107039

5. Gage BF, Waterman AD, Shannon W, Boechler M, Rich MW, Radford MJ. Validation of clinical classification schemes for predicting stroke: results from the National Registry of Atrial Fibrillation. JAMA. 2001 Jun;285(22):2864-70. https://doi.org/10.1001/jama.285.22.2864

6. Olesen JB, Lip GY, Hansen ML, Hansen PR, Tolstrup JS, Lindhardsen $\mathrm{J}$, et al. Validation of risk stratification schemes for predicting stroke and thromboembolism in patients with atrial fibrillation: nationwide cohort study. BMJ. 2011 Jan;342:d124. https://doi.org/10.1136/bmj.d124

7. Pisters R, Lane DA, Nieuwlaat R, de Vos CB, Crijns HJ, Lip GY. A novel user-friendly score (HAS-BLED) to assess 1-year risk of major bleeding in patients with atrial fibrillation: the Euro Heart Survey. Chest. 2010 Nov;138(5):1093-100. https://doi.org/10.1378/chest.10-0134
8. Wallentin L, Yusuf S, Ezekowitz MD, Alings M, Flather M, Franzosi MG, et al. Efficacy and safety of dabigatran compared with warfarin at different levels of international normalised ratio control for stroke prevention in atrial fibrillation: an analysis of the RE-LY trial. Lancet. 2010 Sep;376(9745):975-83. https://doi.org/10.1016/S0140-6736(10)61194-4

9. Hijazi Z, Hohnloser SH, Oldgren J, Andersson U, Connolly SJ, Eikelboom JW, et al. Efficacy and safety of dabigatran compared with warfarin in relation to baseline renal function in patients with atrial fibrillation: a RE-LY (Randomized Evaluation of Long-term Anticoagulation Therapy) trial analysis. Circulation. 2014 Mar;129(9):961-70. https://doi.org/10.1161/CIRCULATIONAHA.113.003628

10. Hart RG, Diener HC, Yang S, Connolly SJ, Wallentin L, Reilly PA, et al. Intracranial hemorrhage in atrial fibrillation patients during anticoagulation with warfarin or dabigatran: the RE-LY trial. Stroke. 2012 Jun;43(6):1511-7. https://doi.org/10.1161/STROKEAHA.112.650614

11. Clemens A, Peng S, Brand S, Brueckmann M, Kansal A, Lim J, et al. Efficacy and cost-effectiveness of dabigatran etexilate versus warfarin in atrial fibrillation in different age subgroups. Am J Cardiol. 2014 Sep;114(6):849-55. https://doi.org/10.1016/j.amjcard.2014.06.015

12. Darwiche W, Bejan-Angoulvant T, Dievart F, Babuty D, Angoulvant $D$, Fauchier L. Bleeding risk in patients treated with dabigatran or vitamin $\mathrm{K}$ antagonist for atrial fibrillation: A meta analysis of adjusted analysis in routine practice settings. Int J Cardiol. 2016 Mar;206:89-92. https://doi.org/10.1016/j.ijcard.2016.01.065

13. Hernandez I, Baik SH, Piñera A, Zhang Y. Risk of bleeding with dabigatran in atrial fibrillation. JAMA Intern Med. 2015 Jan;175(1):18-24. https://doi.org/10.1001/jamainternmed.2014.5398 